\title{
Parental Involvement and Achievement of Secondary School Students
}

\author{
Dr. K. Vijayalakshmi ${ }^{*}$, K. Muniappan ${ }^{2}$
}

\section{ABSTRACT}

Education of the children and their achievement is a strong building block in building a stronger and healthier community. The prosperity of the nation depends upon the today's children and their academic achievement. The role of parental involvement in children's education and their achievement has become a central issue in educational policy and research. This study was aimed at finding out the relationship between parental involvement and achievement of secondary school students in social science. Methods and Materials: A cross sectional, descriptive- correlational research design was adopted for conducting this study at selected schools of Tenkasi district, Tamil Nadu. The sample size of the study was 200 students consisting of 110 boys and 90 girls studying IX standard. Purposive sampling technique was adopted to select the settings and students. The tools used for the study were proforma to collect background characteristics of the students, 59 items-five-point rating scale on Parental involvement and 25 items MCQ Questions with four options on Achievement test in Social science. The data was collected using the predetermined and pretested tools through selfadministration method. Results: Study findings revealed that parental involvement of the students was average in the majority of the students (62\%). Achievement of students in social studies was also found to be average in more than half of the students (57\%). There was a significant positive correlation between parental involvement and achievement of secondary school students ( $\mathrm{r}=0.910, \mathrm{p}<0.001)$. Conclusion: Parental involvement in children's educational activities has direct impact on their academic achievement. Therefore, parents must be encouraged by the psychologists, mental health professionals and teachers to actively participate in their children's wide range of academic activities to bring the best outcome.

Keywords: Parental Involvement, Achievement, Secondary School Students.

\footnotetext{
${ }^{1}$ Professor, Apollo College of Nursing, Chennai, Tamil Nadu, India

${ }^{2}$ PG Faculty, Government Higher Secondary School, Ayikudi, Tenkasi, Tamil Nadu, India

*Responding Author

(C) 2016, K Vijyalakshmi, K Muniappan; licensee IJIP. This is an Open Access Research distributed under the terms of the Creative Commons Attribution License (http://creativecommons.org/licenses/by/2.0), which permits unrestricted use, distribution, and reproduction in any Medium, provided the original work is properly cited.
} 


\section{Parental Involvement and Achievement of Secondary School Students}

The children of today are the future of tomorrow; this powerful statement assumes special significance in our context as children comprise one third of the total population in the country (Children in India, 2012). Every child, on provision of a conducive and an enabling environment, may blossom into an ever fragrant flower, to shine in all spheres of life. This reminds us of the onerous responsibility of the parents, teachers, health professionals and other concerned stake holders of the country that we have to mould and shape their present conditions in the best possible way.

Education is the fourth necessity for man after food, clothing and shelter, in today's competitive world. The education is the process of instruction aimed at the all-round development of individuals, providing the necessary tools and knowledge to understand and participate in day to day activities of today's world (Children in India, 2012). It dispels ignorance and boosts moral values of the individuals. It is the only wealth which cannot be robbed. It forms the basis for lifelong learning and inspires confidence to face challenges of today's competitive world. It provides the skills to individuals to become more self-reliant, enhances the ability to manage health and nutrition and plan for future. Education is also a fundamental requirement in a democracy.

Education is important from various points of view. Its field of activity is so wide that all activities and experiences are embraced in its sphere of work. Education and academic success makes a person to develop confidence and form a strong character useful to his own self and the society of which he is an integral part.

Academic achievement represents performance outcomes of education that indicate the extent to which a person has accomplished specific goals that were the focus of activities in instructional environments, specifically in school (Steinmayr et all, 2014). Therefore, academic achievement should be considered to be a multifaceted construct that comprises different domains of learning. Academic achievement defines whether one can take part in higher education, and based on the educational degrees one attains, influences one's vocational career after education. Besides the relevance for an individual, academic achievement is of utmost importance for the wealth of a nation and its prosperity. Given the individual and societal importance of academic achievement, it is not surprising that academic achievement is the research focus of many scientists; for example, in psychology and educational disciplines. Parental involvement in school assists young students in obtaining the necessary academic competencies for succeeding in school (Hill \& Craft 2003).

Academic achievement is multifaceted construct which is determined by various factors such as study habits, environment, quality of teaching - learning activities, family involvement, heredity and intelligence of the individual. Among these factors, family involvement is one of the 


\section{Parental Involvement and Achievement of Secondary School Students}

important factors that have direct and indirect impact on students' achievement which is further confounded by various other factors.

The influence of family factors on children's education is well established. There is consistent evidence that engaging parents is positively correlated with children's academic achievement, even when prior ability and family social context factors are taken into account (Epstein, 1992; Fan \& Chen, 2001). Children whose parents and/or other significant adults share in their formal education tend to do better in school. The positive findings of parent involvement drive a widely held belief that it plays an important role not only in promoting their own child's academic performance, but more broadly in closing demographic gaps in achievement and assisting in the performance and governance of the school.

Hill and Tyson (2009) did a meta-analysis based on 50 published studies on parent involvement in middle school and found that parental involvement was positively associated with students' achievements. Shatkin and Gershberg (2007), found that parent participation in school governance can foster activism around school issues and lead to significant improvements in school performance.

Although there is an impressive body of literature supporting positive associations between parent involvement and student achievement, there is evidence to suggest a more complex picture of this relationship (Hill \& Tyson, 2009; McNeal, 2012). A number of studies have also revealed that parental involvement had no significant effect on achievement or adjustment (Harris \& Goodall, 2008; Lee \& Bowen, 2006; White, Taylor, \& Moss, 1992).

One possible explanation for these contradictory findings may be the different definitions and measurements of parent involvement used in the studies (Hill \& Tyson, 2009; Lee \& Bowen, 2006). Parent involvement is a broad concept that covers domains from parental aspiration, parenting style, attitudes and values to different direct and indirect methods of involvement (Fan \&Chen 2001; Epstein, 1992).

Despite mixed findings from the literature, a causal relationship between parent involvement and students' academic performance is still not clear since most of the studies were based on crosssectional data (McNeal, 2012). To better understand the mechanisms behind parental involvement and to reduce the risk of academic failure during transition years, more research is called for to quantify and measure the latent construct of parent involvement. At the most basic level, parents can begin encouraging the education of their children by showing that they truly value education themselves.

Parents' involvement in children's education has several forms. Parents who are behaviorally involved participate in activities such as attending school functions and volunteering at the 


\section{Parental Involvement and Achievement of Secondary School Students}

school. Parents who are cognitively involved expose their children to stimulating activities and materials, such as reading books or visiting cultural institutions. Parents who are personally involved communicate positively with their children about school matters. They convey that they value school and expect their children to as well. As a whole, parents can have a positive effect on children's learning by being involved in their schooling and impact on student's achievement in the classroom. In fact, parents who get involved with their child's Education tend to demonstrate good parenting skills, volunteer their time in the school, communicate with faculty and take an active role in school-related decision-making.

Parental involvement is associated with higher student achievement. Student success is higher in a variety of areas including standardized test scores, grades and teacher ratings, when the parents are actively involved in children's educational activities. Students are also more likely to enroll in higher-level programs, pass their classes, attend school regularly, have better social skills and move onto secondary education. Parental involvement has been found to be positively related to student's achievement. It is necessary to determine such involvement among students to understand and guide them better. So that they can become mature citizens and are able to face the challenges of life.

Achievement is the end-product of all educational endeavors. The main concern of all educational efforts is to see that the learner achieves. Social science of education occupies a very eminent place in curriculum both at school and university stages of Education in India. Accordingly, social science becomes a priority area in education, both at compulsory education level as well as the level of specialization.

Parental involvement and achievement of the students are very closely related. Achievement refers to the knowledge attained or skill developed in the school subjects, usually designed by the test scores or by marks assigned by teachers. Therefore, the present study aimed to find out whether there is relationship between these two variables, namely parental involvement and achievement of secondary students. The findings of this research may also be beneficial to educational institutions. The results can be utilized to develop school programs associated with parental involvement in school activities, decisions and homework.

\section{Null Hypothesis:}

1. There is no correlation between Parental involvement and achievement of the students at $\mathrm{p}<0.05$.

\section{METHODS AND MATERIALS}

Study was conducted after obtaining the permission from the concerned authorities of the schools. A Cross sectional, descriptive- correlational research design was adopted for conducting this study. Study was conducted at selected schools of Tenkasi educational district. The 


\section{Parental Involvement and Achievement of Secondary School Students}

population of this study was all the students studying in secondary schools. The sample size of the study was 200 students consisting of 110 boys and 90 girls studying IX standard. Purposive sampling technique was adopted to select the settings and students.

\section{Data Collection Tools}

The tools used for the study were proforma to collect background characteristics of children, rating scale on Parental involvement and Achievement test in Social science.

\section{- PARENTAL INVOLVEMENT TEST}

Parental involvement refers to the participation of parents in every facet of children's education and development activities. In this study it is measured using the tool developed by Paulraja and Alphonse Raj (2008). Tool consists of 59 items measuring the various aspects of parental involvement related to children's education. It is a five point rating scale, score ranging from 1-5 based on the responses of children related to parental involvement (Always, Frequently, Sometimes, Occasionally and Not at all). Hence the total obtainable score is 59 to 295. Obtained score is converted into percentage and interpreted as high (75-100\%), average (50-74\%) and low involvement (Below 50\%) based on the scores obtained by the students. The test- retest reliability co- efficient of the tool was found to be $r=0.84$, indicating the high reliability of the tool.

\section{- ACHIEVEMENT TEST IN SOCIAL SCIENCE}

Achievement Test in Social science was developed by the investigators with the help of concerned teachers to assess the achievement of the students in Social science. It consisted of 25 items - MCQ questions (with one right answer and three distracters) which were selected from the topics from Social science such as History, Geography, Civics and Economics. Time duration of 30 minutes was fixed for conducting the test. The test- retest reliability co- efficient of the test was found to be $r=0.82$.

\section{Data Collection Procedure}

After initial introduction, the researcher obtained written informed consent from the selected students to participate in the study. An assurance was given regarding confidentiality before the data collection procedure. The data was collected using the predetermined and pretested tools through self-administration method in their respective class rooms, during the time allotted by the concerned coordinator of the respective classes.

Collected data was analyzed through appropriate descriptive (Frequency, \%, Mean and SD) and inferential statistics - person's correlation (r) test based on the objectives of the study using SPSS version 18. 


\section{RESULTS}

\section{Table: 1 Frequency and Percentage Distribution of Background Characteristics of the}

Students ( $\mathbf{N}=\mathbf{2 0 0})$

\begin{tabular}{|l|c|c|}
\hline Background characteristics & n & \% \\
\hline Gender & 110 & 55 \\
Male & 90 & 45 \\
Female & & \\
Type of school & 150 & 75 \\
Government School & 50 & 25 \\
Aided management school & & \\
\hline Locality of school & 120 & 60 \\
Rural & 80 & 40 \\
\hline Urban & & \\
\hline
\end{tabular}

Tab 1 indicates that majority of the students were from Government schools (75\%), rural background (60\%) and more than half of them were male children.

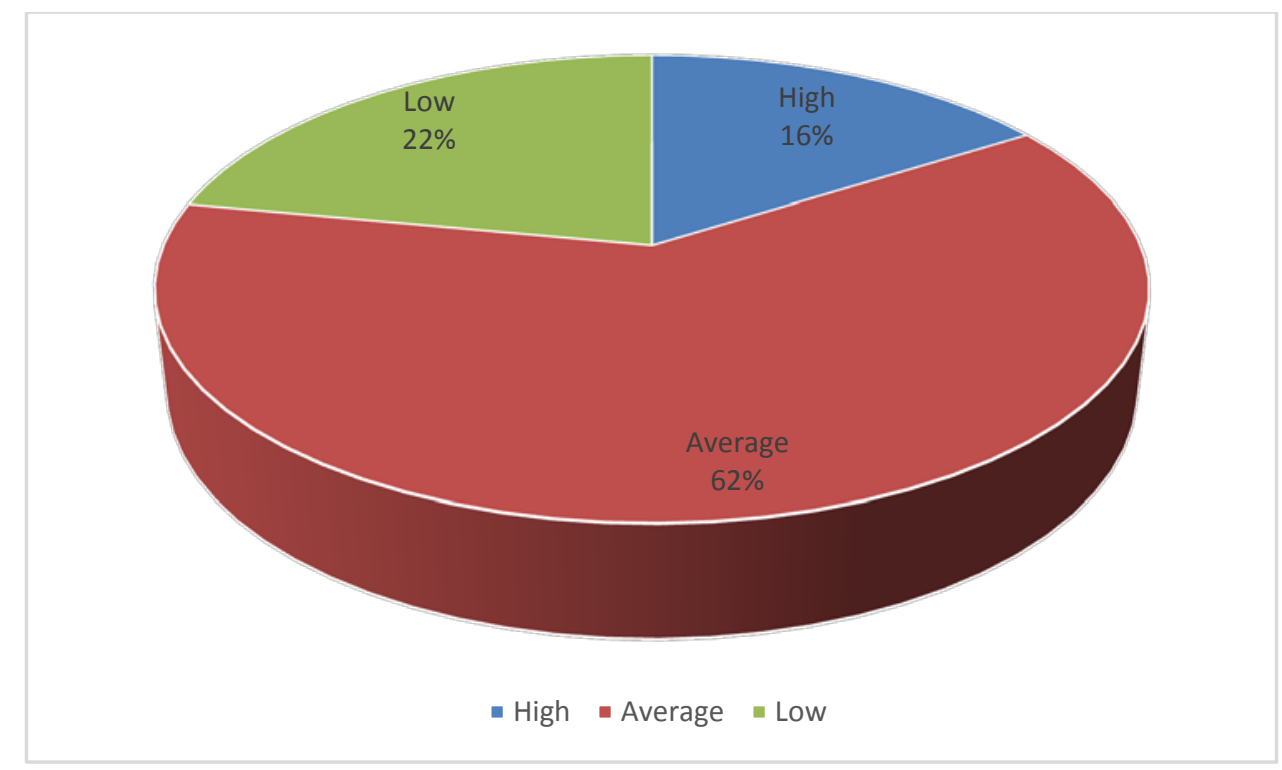

Fig. 1. Level of Parental Involvement of Secondary School Students

Fig 1, depicts that parental involvement of the students was only average in the majority of the students (62\%). 


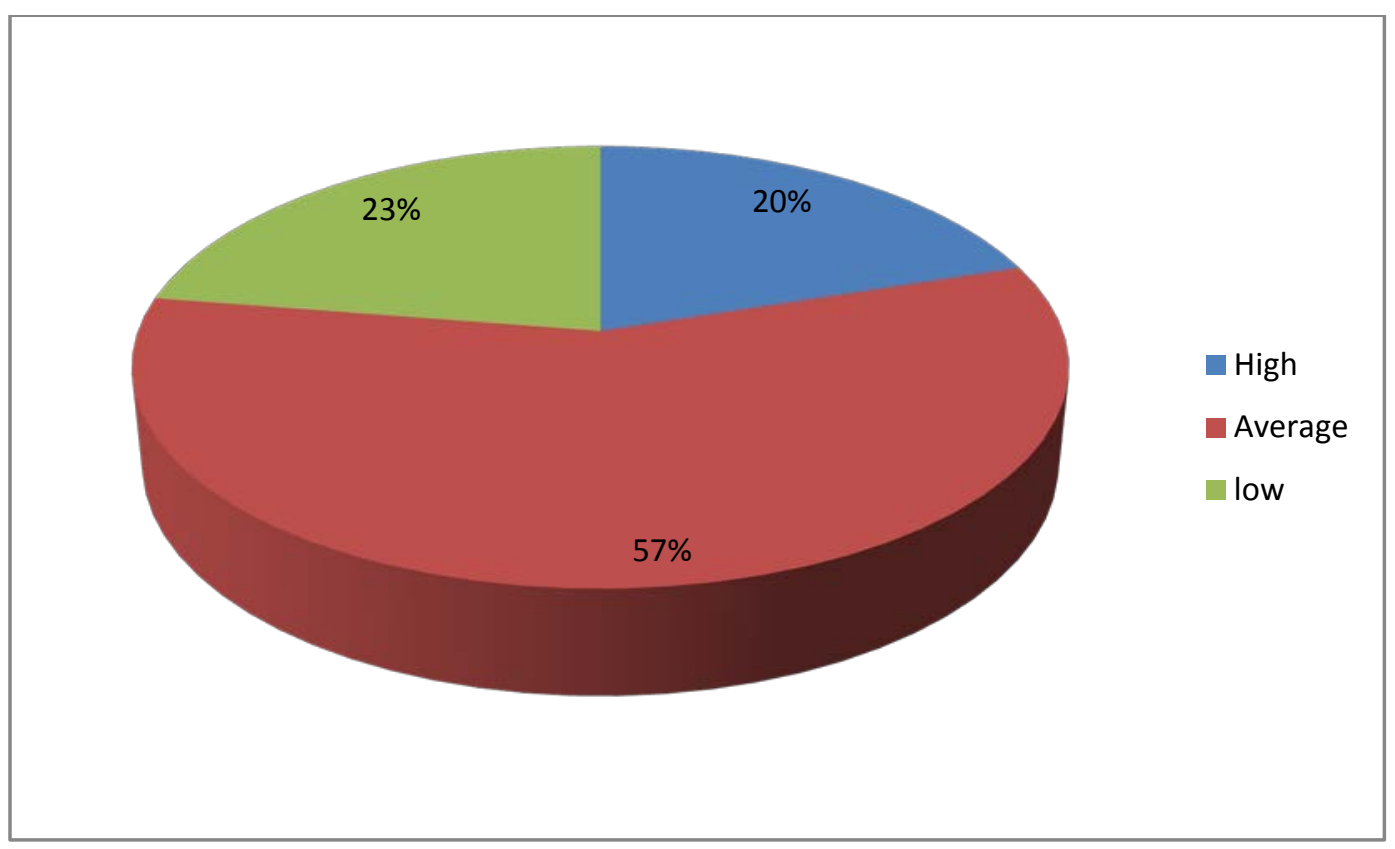

Fig. 2: Level of Achievement of Secondary School Students in Social Studies

Fig 2, reveals that achievement of Secondary School Students in Social Studies was average in more than half of the students (57\%).

Table 2: Relationship Between Parental Involvement and Achievement of Secondary School Students

\begin{tabular}{|c|c|c|c|c|c|}
\hline Variables & $\begin{array}{c}\text { Maximum } \\
\text { score }\end{array}$ & Mean score & SD & r & P- value \\
\hline Parental involvement & 295 & 178 & 48.5 & \multirow{2}{*}{0.91} & $<0.001$ \\
\hline Achievement & 25 & 16 & 4.2 & 0.91 \\
\hline
\end{tabular}

Table 2 shows that the obtained correlation coefficient is significant at 0.001 level $(\mathrm{r}=0.910, \mathrm{p}<0.001)$. This shows that there is significant positive relationship between parental involvement and achievement of secondary school students.

\section{DISCUSSION}

Overall, study findings showed that the parents of the majority of the respondents were moderately involved (average) in their academic activities. Correspondingly almost the same proportionate of the respondents showed better academic achievements. There is significant positive relationship between parental involvement and achievement. Hence the Null Hypothesis 'there is no correlation between Parental involvement and Achievement of the students' is rejected. It indicates the fact that parental involvement influences the achievement of children directly or indirectly. Similar findings are also reported in the study conducted by Rafiq et all

(C) The International Journal of Indian Psychology, ISSN 2348-5396 (e)| ISSN: 2349-3429 (p) | 78 
(2013), where they found association between the two variables i.e. the level of parental involvement in their children's academic activities and level of children's academic achievement.

It is well known fact that, all parents want their children to become successful and caring adults. Similarly, many parents want to be involved with the formal education of their children. However, sometimes it may not be possible to practice in a desirable manner, due to various factors such as lack of time because of tight schedule, ignorance, lack of guidelines etc. They also may not know, where to start, when to find the time, or how to go about making positive connections with the school and related activities. Hence the teachers, Mental health Professionals and other school authorities play vital role in directing the parents by creating awareness on parental involvement and its impact on achievement. It will help the parents in shaping their children's future. At the most basic level, parents can begin encouraging the education of their children by showing that they truly value education themselves.

Parental involvement may be different from culture to culture and society to society. Parental involvement may have different types, which might have differential influence on academic performance of their children. Parental expectations have a greater impact on student's educational outcomes. Parental involvement may include activities like helping children in reading, encouraging them to do their homework independently, monitoring their activities inside the house and outside the four walls of their house, and providing coaching services for improving their learning in different subjects.

The findings of this research may be beneficial to educational institutions. The results can be utilized to develop school programs associated with parental involvement in school activities, decisions and homework. Programs such as these can be implemented to bridge the gap between home and school while improving students' academic achievement. The result of this study might be useful addition in the existing knowledge of education in secondary schools. The findings of the study might be useful for the policy planers in the education planning divisions.

\section{CONCLUSION}

Parental involvement in education of their children has been significantly linked with the quality of education and academic achievement of children. These activities may involve contacts with teachers, checking the attendance of children, monitoring their activities in school, checking their periodical academic progress reports etc. Findings of the study highlight the fact that, parental involvement in children's educational activities has direct impact on their academic achievement. Moulding the children to become a responsible citizen with high achievement is responsibility of the whole society including parents, teachers, health care professionals especially mental health professionals and psychologists, policy makers and concerned others. Health care professionals 
and teachers play vital role in creating awareness among the parents on importance of their role in children's academic achievement by using different strategies and innovative approaches.

\section{Acknowledgments}

The author appreciates all those who participated in the study and helped to facilitate the research process.

\section{Conflict of Interests}

The author declared no conflict of interests.

REFERENCES

Children in India (2012). A Statistical Appraisal. Available in http://mospi.nic.in/Mospi_New/upload/Children_in_India_2012.pdf

Epstein J.L. (1992). School and family partnerships. In M. Alkin (Ed.), Encyclopedia of educational research,(Sixth Edition). New York: MacMillan.

Fan, X. \& Chen, M. (2001). Parental involvement and students' academic achievement: A metaanalysis. Educational Psychology Review, 13, 1-21.

Harris, A. \& Goodall, J. (2008). Do parents know they matter? Engaging all parents in learning. Educational Research, 50, 277-289. doi: 10.1080/00131880802309424.

Hill, N. E., \& Craft, S. A. (2003). Parent-school involvement and school performance: Mediated pathways among socioeconomically comparable African American and Euro-American families. Journal of Educational Psychology, 95, 74-83. doi: 10.1037/0022-0663.95.1.74.

Hill, N. E., \& Tyson, D. F. (2009). Parental involvement in middle school: A meta analytic assessment of the strategies that promote achievement. Developmental psychology, 45, 740-763. doi: 10.1037/a0015362.

Lee, J., \& Bowen, N. K. (2006). Parent involvement, cultural capital, and the achievement gap among elementary school children. American Educational Research Journal, 43, 193218. doi:10.3102/00028312043002193.

McNeal, R. B. (2012). Checking in or checking out? Investigating the parent involvement reactive hypothesis. The Journal of Educational Research, 105(2), 79-89. doi:10.1080/00220671.2010.519410.

Paulraja and Alphonse Raj (2008). Parental involvement and achievement of secondary school children. Ph. D Thesis submitted to Manonaniam Sundarnar University, Tamil Nadu, India.

Rafiq H M W, Fatima T,Sohail M H, Saleem M, Khan M A. Parental Involvement and Academic Achievement; A Study on Secondary School Students of Lahore, Pakistan. International Journal of Humanities and Social Science 3( 8), 209-223.

Shatkin, G., \& Gershberg, A. I. (2007). Empowering parents and building communities the role of school-based councils in educational governance and accountability. Urban Education, 42, 582-615. doi: 10.1177/0042085907305044. 
Steinmayr R, Meibner A, Anne F. Weidinger and Wirthwein L. Academic Achievement. Oxford Index. ISBN: 9780199756810. Published online July 2014 DOI: http://dx.doi.org/10.1093/obo/9780199756810-0108

Sun L. (2015). Parent Involvement and Science Achievement During Students' Transition Years from Elementary School to Middle School: A Cross-Lagged Panel Analysis Using EclsK" Theses and Dissertations--Educational Policy Studies and Evaluation. Paper 37. Available in http://uknowledge.uky.edu/epe_etds/37

White, K. R., Taylor, M. J., \& Moss, V. D. (1992). Does research support claims about the benefits of involving parents in early intervention programs?.Review of Educational Research, 62, 91-125. doi: 10.3102/00346543062001091.

How to cite this article: K Vijyalakshmi, K Muniappan (2016), Parental Involvement and Achievement of Secondary School Students, International Journal of Indian Psychology, Volume 3, Issue 4, No. 65, ISSN 2348-5396 (e), ISSN: 2349-3429 (p), DIP: 18.01.142/20160304, ISBN: 978-1-365-34680-4 